\title{
SEGURANÇA ALIMENTAR E DESENVOLVIMENTO RURAL: LIMITES E POSSIBILIDADES DO PROGRAMA DE AQUISIÇÃO DE ALIMENTOS DA AGRICULTURA FAMILIAR, EM MUNICÍPIOS DO SUL GAÚCHO
}

\begin{abstract}
Cláudio Becker ${ }^{1}$ e Flávio Sacco dos Anjos ${ }^{2}$
Este artigo aborda o processo de implementação do Programa de Aquisição de Alimentos (PAA) e suas implicações no contexto do desenvolvimento rural e da segurança alimentar e nutricional das famílias beneficiadas. O estudo que originou o presente trabalho foi realizado junto a sessenta agricultores familiares distribuídos em três municípios do extremo sul gaúcho. As informações coletadas junto às comunidades rurais compuseram um banco de dados, que serviram de base para a nossa análise. Os autores objetivam demonstrar que a intervenção estatal pode ser capaz de interferir positivamente na dinâmica produtiva das famílias rurais, auxiliando na geração de renda, manutenção das práticas e cultivos tradicionais, na produção agroecológica, possibilitando, desta forma, novas perspectivas para a sua reprodução social. Através do fornecimento de alimentos ao PAA, grupos sociais marginalizados puderam ser incluídos no processo produtivo e a organização social da produção se viu favorecida nestas localidades. A valorização dos produtos locais/regionais pelo programa, atuou na retomada e manutenção das práticas de autoconsumo entre os beneficiados. Não menos importante, diagnosticamos diversos novos processos sociais provocados junto aos organismos que operam com o PAA nos municípios analisados, tornando-se esta política pública e as instituições a ela implicadas, como precursoras de uma nova dinâmica de desenvolvimento.
\end{abstract}

Palavras - chave: segurança alimentar, desenvolvimento rural, agricultura familiar, políticas públicas.

\section{FOOD SECURITY AND RURAL DEVELOPMENT: LIMITS AND POSSIBILITIES OF THE FOOD ACQUISITION PROGRAMME OF THE FAMILY FARMING IN SOUTHERN RIO GRANDE DO SUL STATE, BRAZIL}

This article discusses the implementation process of Food Acquisition Programme and its implications in the context of rural development and food security of the benefited with this programme. The study that originated this work was done with sixty family farmers spread across three municipalities in southern of Rio Grande do Sul state, Brazil. The information gathered from rural communities shaped a database, which formed the basis for our analysis. The authors seek to demonstrate that State intervention can be capable of positive interfering in dynamic productive of the farmers through income generation, maintenance and traditional farming practices, agroecologic production, thereby new perspectives for their social reproduction. Through the provision of food to the Food Acquisition Programme, marginalized social groups could be included in the production process and the social organization of production was favoured in these localities. The recovery of local/regional products by the programme, he served in the resumption and continuation of self-consumption practices was benefited. Not least, diagnosticamos several new social processes caused in the institutions that are accessing the PAA in municipalities analyzed, becoming this public policy and institutions it involved forerunners a new dynamic development.

Key words: food security, rural development, family farming, public policies.

\footnotetext{
${ }^{1}$ Doutorando em Sistemas de Produção Agrícola Familiar (Universidade Federal de Pelotas), Departamento de Ciências Sociais Agrárias, Campus Universitário s/n, Pelotas-RS, Caixa Postal 354, CEP 96010-900. Tel/fax: (53) 3275-7256. E-mail: cldbecker@yahoo.com.br

${ }^{2}$ Doutor em Sociologia pelo Instituto de Sociología y Estudios Campesinos (Universidad de Córdoba). Professor do Departamento de Ciências Sociais Agrárias e dos Programas de Pós-Graduação em Sistemas de Produção Agrícola Familiar e do Mestrado em Ciências Sociais (Universidade Federal de Pelotas). Bolsista de Produtividade 2 do $\mathrm{CNPq}$
} 


\section{Introdução}

O presente artigo examina o tema das políticas públicas relativas à segurança alimentar e nutricional das comunidades rurais, em um contexto sócio-histórico onde a agricultura familiar experimentou significativas transformações nas últimas décadas. Trata-se de uma aproximação que se busca desenvolver acerca da evolução do Programa de Aquisição de Alimentos (PAA) no sul gaúcho, mais especificamente junto aos municípios de Pelotas, Canguçu e São Lourenço do Sul.

O cenário atual revela importantes mudanças que convergem para novos papéis atribuídos à agricultura familiar no contexto nacional, vista agora como segmento estratégico para a produção de matérias primas e abastecimento alimentar das populações, bem como à própria dinâmica de desenvolvimento rural que se quer impulsionar no marco das políticas públicas. De acordo com Abramovay ${ }^{[1]}$, a agricultura familiar não somente supõe a garantia do abastecimento alimentar do país, mas também, que esta escolha representa uma opção estratégica em favor de um desenvolvimento mais equilibrado da sociedade. A agricultura familiar seria o espaço para onde convergem desenvolvimento e equidade.

Dados do último censo agropecuário dão conta que existem no Brasil cerca de 4,4 milhões de estabelecimentos, o que corresponde a $84,4 \%$ do universo de explorações agrárias atualmente existentes em nosso país, sendo estas responsáveis por 38\% do valor bruto da agropecuária nacional, não obstante ocupar apenas um quarto da superfície agricultável[2].

No sentido de balizar as abordagens utilizadas na pesquisa, torna-se imprescindível esclarecer quais as concepções de segurança alimentar e de política pública em que nos baseamos para a aproximação que desencadeamos junto à realidade concreta.

A formulação de políticas públicas pode ser analisada de diversas formas, principalmente em relação aos seus resultados finais. Parte-se do suposto que várias ações governamentais convergem para alcançar a emancipação dos indivíduos e coletividades, particularmente os que se vêem submetidos à privação de suas liberdades substantivas no sentido atribuído por Amartya Sen[3]. Segundo este autor, a provisão pública torna-se essencial para interferir em distorções historicamente consolidadas e para oferecer oportunidades aos segmentos estratégicos, como é precisamente o caso da agricultura familiar.
Por outra parte, é preciso mencionar que a análise da segurança alimentar pressupõe interpretações ou acepções distintas ${ }^{3}$. Trata-se, em última instância, de uma categoria que gera grande controvérsia por seu conteúdo e implicações, incluindo atualmente a questão da soberania e da sustentabilidade alimentar. No primeiro caso, concede-se primazia à autonomia alimentar dos países, estando associada à geração de emprego dentro do país, menor dependência das importações e uma menor exposição a flutuações de preços do mercado internacional. A sustentabilidade refere-se à capacidade de promover a satisfação das necessidades alimentares da população no curto prazo, sem que haja sacrifício dos recursos naturais, tornando possível a preservação das condições ecológicas que garantam a disponibilidade de alimentos para as gerações futuras ${ }^{[4]}$. Nesta perspectiva, o tema passou a ter um caráter estratégico para o desenvolvimento social, sendo a principal proposta de política governamental do Brasil, durante a última década, na área de alimentação e nutrição ${ }^{4}$.

É possível notar, ao fim e ao cabo, a amplitude deste conceito, que contempla aspectos que afetam não somente à disponibilidade de alimentos, mas também a sua qualidade nutritiva. Enfatiza os aspectos do acesso, qualidade e suficiência, valorizando os hábitos alimentares adequados, ao mesmo tempo em que situa a segurança alimentar e nutricional como condição elementar de cidadania.

De acordo com Valente[7], o tema ganhou destaque a partir do reconhecimento das conseqüências nefastas advindas da revolução verde, as quais ampliaram as discussões acerca da insegurança alimentar que acomete países e continentes que se incorporaram a esse padrão produtivo, marcado pela ênfase na busca incessante de incremento de produtividade dos cultivos e criações e na omissão em relação aos impactos produzidos pelo uso indiscriminado de adubos sintéticos e agrotóxicos.

Destarte, há que ter em mente que a insegurança alimentar das populações não poderia ser tratada exclusivamente pelo prisma do consumo de uma dieta calórica mínima. De acordo com Sen[3], a fome relacionase ao funcionamento de toda economia e, mais amplamente, à ação das disposições políticas e sociais que podem influenciar, direta ou indiretamente, o potencial das pessoas para adquirir alimentos e obter saúde e nutrição. Assim sendo,

\footnotetext{
${ }^{3}$ Sobre esta discussão, consultar entre outros, Maluf[5] e Sacco dos Anjos et al.[6]. ${ }^{4}$ Chama-se a atenção para a reativação do Consea (Conselho Nacional de Segurança Alimentar e Nutricional) ocorrida em 2003 e de três conferências nacionais promovidas, desde, então para discutir este tema na sociedade brasileira.
} 
Subnutrição, fome crônica e fomes coletivas são influenciadas pelo funcionamento de toda a economia e de toda a sociedade - não apenas pela produção de alimentos e de atividades agrícolas. É crucial examinar adequadamente as interdependências econômicas e sociais que governam a incidência da fome no mundo contemporâneo. Os alimentos não são distribuídos na economia por meio da caridade ou de algum sistema de compartilhamento automático. O potencial para comprar os alimentos tem que ser adquirido. (SEM ${ }^{[3]}$, p.190. itálico no original)

Nos últimos anos a questão alimentar converteu-se em matéria de importantes debates e objeto privilegiado de intervenção estatal. Chegou inclusive a ser assumida como peça da retórica oficial e de grupos de interesse na arena política que culminou com a vitoriosa campanha de Luís Inácio Lula da Silva à presidência da república em 2002[8]. Não obstante, a luta contra a fome é resultante de um processo histórico de mais de duas décadas de mobilização social. O Programa Fome Zero (PFZ) é, em verdade, um grande marco através do qual se aglutina um conjunto de programas de intervenção, tanto de caráter imediato quanto de natureza estrutural, implementados por meio de instrumentos de políticas públicas.

De acordo com Takagi et al.[7], tornava-se imperativo promover a articulação das políticas estruturais com as políticas emergenciais de combate à fome. Entre as políticas estruturais prioritárias, destacamse as políticas de geração de emprego e renda, como a expansão do microcrédito, a qualificação profissional, o estímulo a micro empreendimentos, a realização de uma reforma agrária que amplie o acesso à terra, a expansão da previdência social para as pessoas em regime informal de trabalho, incluídas as famílias rurais, e algumas adequações na política agrícola no âmbito da comercialização e acesso aos mercados.

É nesse plano que se inscrevem algumas ações do PFZ, que foi concebido para articular, como já dissemos, um conjunto amplo de políticas públicas. De um lado, temos as políticas de transferência direta de renda (bolsa-escola, bolsa-família, etc.), distribuição de alimentos, merenda escolar, etc. De outra parte constam ações voltadas à reordenação fundiária, apoio à instalação de jovens agricultores, acesso a políticas públicas de fomento à produção da agricultura familiar, entre outras. É exatamente neste contexto que emerge o Programa de Aquisição de Alimentos, objeto central de nossa análise.

O PAA é um instrumento de política pública instituído em 2003, cujo objetivo é garantir o acesso aos alimentos em quantidade, qualidade e regularidade necessários às populações em situação de insegurança alimentar e nutricional e promover a inclusão social no campo por meio do fortalecimento da agricultura familiar [10]. O programa possui um amplo espectro de atuação, agindo simultaneamente na tríade produçãocomercialização-consumo. Desta forma, oferece-nos algumas possibilidades interessantes no sentido de explorar as múltiplas dimensões da segurança alimentar, bem como certas externalidades previstas e imprevistas na dinâmica que acompanha essa política pública.

Em meio a profundas modificações que abalam a estrutura das formas familiares de produção, torna-se decisiva a atuação do Estado no sentido de propor medidas destinadas a aplacar os efeitos de uma crise que alcança o conjunto das comunidades rurais, particularmente nessa região da geografia gaúcha. Cabe destacar, que neste território a agricultura familiar passa por um período de profunda especialização produtiva, que tem na produção de tabaco sua maior expressão.

O cultivo de alimentos e um conjunto de linhas de produção (suínos, batata, pêssego, aspargo, morango, entre outras) que, até então, asseguravam a reprodução social de milhares de famílias rurais, vêm paulatinamente sucumbindo ao monocultivo do fumo. Analisando as informações sobre a produção agrícola municipal, verificamos que a partir do ano 2000, enquanto todas as demais plantações apresentaram redução tanto na área cultivada quanto na quantidade produzida, o tabaco mais do que dobrou em ambos os quesitos ${ }^{[1]}$.

Vários são os fatores que contribuíram para esta situação. Todavia, não resta dúvida de que as restrições na comercialização da produção e o acesso aos mercados têm sido decisivos para que os agricultores familiares se vissem forçados a alterar sua dinâmica produtiva tradicional, conforme demonstrou o estudo de Hirai ${ }^{[12]}$.

Verificamos que no enfrentamento dos obstáculos postos e como expressão das estratégias de sobrevivência da agricultura familiar, diversos agricultores optaram por unirem esforços no sentido de construírem suas próprias estruturas de enfrentamento aos desafios da sociedade contemporânea. Wilkinson ${ }^{[13]}$ afirma que o futuro da produção agrícola familiar depende menos da competitividade definida nos estreitos limites tecnológicos e organizacionais, do que do efetivo surgimento de uma coalizão de atores comprometidos com a redefinição das prioridades econômicas regionais, a partir do potencial produtivo do sistema de produção familiar.

Já no começo desse novo milênio surgiram algumas iniciativas por parte do poder público, voltadas à questão da comercialização dos produtos oriundos da 
agricultura familiar. Isso ocorreu em determinados municípios do Rio Grande do Sul, onde se assistiu à emergência das primeiras experiências de compra de alimentos para a merenda escolar nas escolas públicas estaduais. O consumo coletivo manifesta-se por meio da ação do poder público, na implementação de programas institucionais, os quais expressam uma faceta do que se passou a denominar de mercado institucional[13].

Contudo, nenhuma destas iniciativas teve repercussão equivalente ao Programa de Aquisição de Alimentos (PAA). Esta iniciativa surgiu em meados de 2003, como uma das ações do Programa Fome Zero, tendo como fonte financiadora ${ }^{5}$ o Ministério do Desenvolvimento Social e, diferentemente das demais políticas ditas compensatórias, se propunha a estabelecer uma nova relação entre, de um lado, os beneficiários de programas sociais, quais sejam, as pessoas em risco de insegurança alimentar, e de outro, os agricultores familiares, dedicados ao fornecimento de gêneros alimentícios produzidos em seus próprios estabelecimentos.

Um dos projetos PAA de maior envergadura daquela época foi estabelecido justamente no município de Pelotas-RS, tendo cerca de 2.600 famílias como beneficiários consumidores e cerca de 1.000 famílias de agricultores familiares como fornecedores credenciados.

O advento deste instrumento de política pública pode ser visto como um via de desenvolvimento rural singular, a qual, em sua essência, não contempla apenas o plano econômico, mas, sobretudo, a melhoria da qualidade de vida das populações rurais e o estabelecimento de novas relações com outros atores econômicos. Ações, neste sentido, podem contribuir para que os agricultores familiares enfrentem os desafios do mundo contemporâneo, à medida que simultaneamente oportunizam a inserção nos mercados e a geração de trabalho e renda junto aos beneficiários.

O problema de pesquisa que sustenta o presente projeto centra-se em algumas grandes questões. Nesse sentido, indagamo-nos: como os agricultores familiares se reconhecem no processo de comercialização atinente ao referido programa? Por outro lado, quais as perspectivas que se abriram a partir da operacionalização do PAA em suas localidades? Houve modificações nas unidades produtivas, como a retomada e/ou ampliação dos cultivos tradicionais e a diversificação produtiva? Este

\footnotetext{
${ }^{5}$ Em 2006 o Ministério do Desenvolvimento Agrário (MDA) também passa a disponibilizar recursos para o PAA, sendo o programa operado pela Companhia Nacional de Abastecimento (Conab). Maiores detalhes podem ser obtidos em Müller ${ }^{[14]}$.
}

programa trouxe novas expectativas para o desenvolvimento da atividade agrícola? Estas são questões que nos parecem essenciais à compreensão do real impacto causado por este instrumento de intervenção estatal, o qual consideramos como representativo de uma política pública tipicamente estruturante.

Neste sentido, estabelecemos como principais objetivos do nosso estudo: i) analisar como o PAA, enquanto mercado institucional, tem influenciado na dinâmica produtiva das famílias rurais, do ponto de vista das rendas obtidas, da manutenção e ampliação dos cultivos e das práticas tradicionais, bem como, do aprimoramento das relações destes agricultores com o mercado; ii) avaliar os impactos provocados pelo programa na questão da segurança alimentar, nas práticas de autoconsumo e na valorização dos hábitos alimentares e da produção local, possibilitados pela garantia da comercialização destes produtos.

\section{Metodologia}

A definição do universo empírico para a realização da nossa pesquisa não se deu por acaso. Até o momento em que se iniciou nossa investigação, ocorrida no segundo semestre de 2009, havíamos acumulado seis anos de atuação em municípios do extremo sul gaúcho, fato que, por si só, ganha relevo tanto do ponto de vista do número de experiências, dados e informações, extremamente relevantes para avaliar a eficácia desses instrumentos de política pública. Ressaltamos ainda, que se optou em realizar o estudo em mais de um local, com a finalidade de detectar possíveis diferenças na forma de operação e na percepção dos beneficiários. Desta forma, elegemos os municípios de Pelotas, Canguçu e São Lourenço do Sul, como representativos dos propósitos a que este estudo se destina.

A escolha dos agricultores familiares seguiu alguns procedimentos que nos pareceram mais adequados para os objetivos da pesquisa. Uma amostra aleatória dos produtores familiares poderia ter sido um caminho para assegurar, do ponto de vista estatístico, a representatividade dos entrevistados, considerando um contingente aproximado de 850 famílias rurais beneficiadas no contexto dos três municípios que elegemos como recorte de realidade.

Optamos, entretanto, por tomar as instituições participantes do PAA como ponto de partida para chegar a uma amostra de 60 famílias a serem entrevistadas, a qual consideramos como factível para dar cabo do problema e dos objetivos da pesquisa. As instituições 
correspondem à Cooperativa Sul Ecológica ${ }^{6}$ (Pelotas); UNAIC $^{7}$ (Canguçu) e, COOPAR ${ }^{8}$ (São Lourenço do Sul), às quais tomamos como base para estabelecer a distribuição, o mais equilibrada possível, dos entrevistados, levando em conta o contingente de agricultores participantes que a cada uma delas corresponde.

Convém salientar, que analisamos uma modalidade9 específica pelo qual o PAA é operado, qual seja a Compra com doação simultânea (CPR Doação), que visa promover a articulação entre a produção de agricultores familiares e as demandas locais de suplementação alimentar e nutricional de escolas, creches, abrigos, albergues, asilos, hospitais públicos, atendendo também aos programas sociais da localidade, tais como bancos de alimentos, restaurantes populares e cozinhas comunitárias. É também a modalidade em que os alimentos vão direto do agricultor à entidade responsável pela distribuição dos mesmos, sendo necessária uma grande organização, produtiva e social neste processo. Especificamente, a CPR Doação é o mecanismo pelo qual efetivamente os agricultores familiares acessam o PAA, através de suas organizações, nos municípios em que foi realizada a nossa pesquisa.

O instrumental metodológico que se utilizou para dar cabo do nosso problema de pesquisa contemplou o uso técnicas de investigação de caráter quantitativo e qualitativo. Para avaliar o programa a partir da ótica dos atores sociais envolvidos e auxiliar na coleta de dados, a aplicação de questionários mostra-se como ferramenta útil para reunir um conjunto de informações suficientes para responder aos questionamentos anteriormente referidos. A adoção de outros instrumentos, como é o caso de entrevistas com base em um roteiro prévio, composto por perguntas fechadas e abertas, torna-se igualmente útil para atingir tais propósitos. A análise do programa, na perspectiva dos atores responsáveis por sua operacionalização, mormente as entidades contempladas pelo PAA, compreendeu outra dimensão do itinerário metodológico do estudo. Neste sentido, identificaram-se, em cada um dos municípios pesquisados, os atores sociais estratégicos que

\footnotetext{
6 A Cooperativa Sul Ecológica de Agricultores Familiares Ltda é uma cooperativa regional que congrega agricultores ecologistas, que conta atualmente com 220 cooperados, distribuídos em oito municípios.

7 A UNAIC (União das Associações Comunitárias do Interior de Canguçu e região) é formada por 38 pequenas associações e grupos de agricultores familiares.

8 A Cooperativa Mista dos Pequenos Agricultores da Região Sul Ltda (COOPAR), possui mais de dois mil agricultores familiares em seu quadro social.

${ }^{9}$ Para maiores detalhes sobre esta e as demais modalidades que o PAA opera, consultar entre outros Müller[14].
}

participam ativamente das atividades operacionais do programa.

A apreciação isolada dos dados quantitativos correspondentes à operação do programa é obviamente limitada, razão pela qual tornou-se essencial a montagem de um banco de dados primários a partir da aplicação dos questionários e realização de entrevistas, visando contemplar as questões postas. As informações coletadas compuseram um banco de dados no formato estatístico SPSS (Statistical Package Social Science), através do qual procedemos à análise e cruzamento das variáveis.

Durante a realização da entrevista com os agricultores valemo-nos ainda da observação como uma forma de extrair elementos para além daqueles que havíamos previsto nas questões previamente elaboradas. As observações foram devidamente registradas em caderneta de campo, auxiliando posteriormente na análise de questões relevantes.

Nossa pesquisa trata-se efetivamente de um estudo de caso, que de acordo com Yin ${ }^{[15]}$ é uma forma de estratégia de pesquisa intensiva, na qual se leva em consideração a descrição e a compreensão de fenômenos sociais complexos, através das relações dos fatores entre si, em um contexto socialmente determinado.

\section{Resultados e discussão}

Esse estudo esteve voltado a diagnosticar se de fato os beneficiados com o PAA formavam um contingente de agricultores familiares que obtiveram melhorias efetivas em suas unidades produtivas a partir da sua inserção no programa, principalmente em relação à sua dinâmica produtiva e a segurança alimentar e nutricional do grupo familiar. Assim sendo, nas entrevistas realizadas procurou-se extrair informações que respondessem a estas inquietações, não obstante examinar outras questões pertinentes à análise sobre a eficácia desta política pública.

Através dos dados da Tabela 1 tem-se um panorama geral da produção das unidades produtivas pesquisadas, no qual se apresenta a distribuição dos entrevistados quanto aos grupos de produtos ${ }^{10}$ que fornecem ao PAA. As hortaliças e frutas foram os produtos fornecidos pela maioria das famílias, seguidos dos grãos, raízes, tubérculos e produtos agroindustrializados, respectivamente.

\footnotetext{
${ }^{10}$ A classificação foi realizada da seguinte forma: a) Grãos: feijão, milho e arroz; b) Hortaliças e frutas: abóbora, couve, cenoura, beterraba, cebola, laranja e bergamota; c) Raízes e tubérculos: batata, batata doce e mandioca; d) Agroindustrializados: suco, schimier (doce em pasta), mel e ovos.
} 
Tabela 1 Distribuição dos entrevistados segundo o grupo de produtos alimentares fornecidos ao PAA.

\begin{tabular}{lc}
\hline \multicolumn{1}{c}{ Grupo de produtos } & Número de famílias \\
\hline Grãos & 38 \\
Hortaliças e frutas & 31 \\
Raízes e tubérculos & 29 \\
Produtos & 08 \\
agroindustrializados & \\
\hline \multicolumn{1}{c}{ Total } & $\mathbf{1 0 6}^{*}$
\end{tabular}

Fonte: Pesquisa de Campo (2009).

* O total foi superior ao tamanho da amostra pelo fato da maioria das famílias fornecerem produtos de mais de um destes grupos.

Salienta-se que os produtos da agroindústria familiar são adquiridos pelo programa, condição que incentiva os agricultores ao esforço de agregação de valor e o processamento dos produtos em seus próprios estabelecimentos, visto que esse processo é uma prática tradicional entre os descendentes de europeus que colonizaram a região ${ }^{11}$. Desta forma, esta prática, antes tão presente no cotidiano destas famílias, se viu agora favorecida através da operação do PAA.

Outro ponto de destaque é que oito famílias entrevistadas forneciam alimentos enquadrados em três dos grupos apresentados na Tabela 1. De um modo geral, as unidades produtivas possuíam uma considerável diversificação das suas atividades e tipos de cultivos. Não obstante, doze famílias entrevistadas produziam unicamente grãos para o programa. Este tipo de produção (especialmente milho) estava comumente associado $^{12}$ à produção de tabaco. Notou-se que, nestes casos, o programa assumia uma condição exclusiva de mercado, ou seja, de venda de parte da produção, assumindo um baixo impacto na renda e na diversificação da exploração familiar.

Sobre a produção de fumo, esta atividade estava presente em dezesseis das sessenta unidades produtivas investigadas. Durante as entrevistas houve diversos relatos da especialização produtiva decorrente do cultivo do tabaco nas comunidades em que os nossos agricultores residiam, ou seja, a renda agrícola das familias dependeria unicamente desta produção. Vários dos nossos entrevistados declararam que assumiram uma condição de fornecedores de alimentos básicos para seus

\footnotetext{
${ }^{11}$ É o que evidencia Grando[16] em seu estudo sobre a 'Colônia Francesa' no interior do município de Pelotas. "[...] as fábricas artesanais de doces, passas e conservas de frutas e legumes que surgiram em Pelotas, nos dois últimos decênios do século passado, desenvolvidas a partir do campesinato ali formado".

${ }^{12}$ Trata-se de uma associação de caráter técnico, tendo em vista o objetivo do produtor em rentabilizar o adubo utilizado na produção de fumo mediante $o$ cultivo de grãos em sucessão.
}

vizinhos que se converteram em produtores especializados de tabaco.

A Tabela 2 apresenta a distribuição dos entrevistados quanto ao sistema produtivo utilizado na produção dos alimentos destinados ao PAA. Nota-se, que nada menos que $60,0 \%$ dos agricultores utilizam o sistema orgânico/ecológico ${ }^{13}$, para esta produção. Este fato chamou-nos a atenção, pois encontramos evidências de que o programa serviu, entre outros aspectos, para impulsionar decisivamente a produção ecológica na região. Por outro lado, este dado serve para desmitificar a tese de que as pessoas de escassos recursos, como é precisamente o caso dos beneficiários-consumidores, não possam ter acesso a alimentos de qualidade, como é precisamente o caso dos produtos ecológicos.

Tabela 2 Distribuição dos entrevistados segundo o sistema produtivo adotado na produção dos alimentos destinados ao PAA.

\begin{tabular}{ccc}
\hline $\begin{array}{c}\text { Sistema de } \\
\text { produção }\end{array}$ & $\begin{array}{c}\text { Número de } \\
\text { famílias }\end{array}$ & Percentual (\%) \\
\hline Orgânico/Ecológico & 36 & 60,0 \\
Convencional & 24 & 40,0 \\
\hline Total & $\mathbf{6 0}$ & $\mathbf{1 0 0 , 0}$ \\
\hline
\end{tabular}

Fonte: Pesquisa de Campo (2009).

Não obstante, há que sopesar o fato do programa oferecer um bônus de 30\% sobre os preços correspondentes aos produtos convencionais para o caso de alimentos oriundos de sistemas produtivos de base ecológica. Este incentivo monetário foi referido pela ampla maioria dos nossos entrevistados $(85,0 \%)$ como um atrativo a iniciar um processo de conversão agroecológica ${ }^{14}$. Da mesma forma, a partir do seu ingresso no PAA, muitos agricultores efetivamente realizaram esta opção. É precisamente o caso de 37 entrevistados que iniciaram a produção de base ecológica à época em que ingressaram no programa, sendo que alguns destes já possuíam alguma experiência anterior, mas que, nesse caso, visualizaram no PAA a possibilidade de consolidarem este sistema produtivo.

O apoio fornecido aos agricultores que produzem alimentos orientados por uma produção "limpa", expressa-se na quantidade considerável de produtos adquiridos pelo PAA nos municípios que

13 Esta é a designação que o PAA confere aos produtos concebidos em um sistema produtivo que não utilize produtos químicos sintéticos e adubos de alta solubilidade. Todavia, reconhecemos as diferenças existentes entre a produção orgânica e a produção agroecológica. Neste sentido, utilizaremos a expressão sistemas de produção de base ecológica para nos referirmos aos processos que visam a obtenção de alimentos de acordo com os princípios agroecológicos.

${ }^{14}$ De acordo com Gliessman ${ }^{[17]}$, refere-se a um processo gradual de mudança, através do tempo, nas formas de manejo dos agroecossistemas, tendo-se como meta a passagem de um modelo agroquímico de produção a estilos de agricultura que incorporem princípios, métodos e tecnologias de base ecológica. 
operam o programa no sul gaúcho, conforme ilustra a a Tabela 3. Encontramos evidências de que o PAA serviu para impulsionar a produção de alimentos ecológicos. Verificamos, neste caso, que o programa não atuou somente sobre a ótica do sistema produtivo, mas inclusive nas demais características concernentes à qualidade de vida destas famílias, como no caso de chamar a atenção para a importância de uma alimentação satisfatória e saudável.

Tabela 3. Fornecimento médio anual de produtos orgânicos/ecológicos ao PAA Doação Simultânea, no território Zona Sul do RS.

\begin{tabular}{lc}
\hline \multicolumn{1}{c}{ Produtos } & Quantidade (kg) \\
\hline Feijão preto & 94.700 \\
Batata & 85.800 \\
Abóbora & 79.000 \\
Repolho & 43.000 \\
Arroz & 31.600 \\
Cebola & 29.700 \\
Farinha de milho & 20.500 \\
Cenoura & 17.500 \\
Beterraba & 12.500 \\
\hline \multicolumn{2}{c}{ Total } \\
\hline
\end{tabular}

Fonte: Pesquisa de campo (2009).

Em termos operacionais, a diversidade dos gêneros alimentícios provenientes dos agricultores familiares compõe uma "sacola" de produtos, que contempla um grupo amplo de artigos, pressupondo obviamente, a sazonalidade de produção por se tratarem de produtos regionais. Assim sendo, há uma variação na composição das sacolas durante todo o ano. No que tange à diversidade dos gêneros ofertados, ressalta-se que essa é uma característica emblemática da agricultura familiar, sendo sem sombra de dúvidas, um dos atributos mais valorizados pelo PAA.

Os dados da Tabela 4 indicam a relação dos produtos constantes no programa no município de Canguçu-RS. Neste caso, a entrega de produtos é realizada por duas associações e duas cooperativas de agricultores familiares, sendo distribuídos a associações de bairro, entidades assistenciais, comunidades religiosas, escolas de educação infantil e de ensino fundamental. Estas entidades são responsáveis pela distribuição às pessoas em situação de insegurança alimentar, devidamente cadastradas no programa.

Ao examinarmos os dados da Tabela 4 percebemos um considerável volume de hortaliças e frutas entre os alimentos absorvidos pelo PAA. Neste sentido, a dieta alimentar dos beneficiários consumidores se vê favorecida sobremaneira, conforme pudemos detectar junto a alguns representantes dos comitês gestores nos municípios pesquisados. Não obstante, detecta-se também a presença de diversos produtos regionais, a exemplo da bergamota, farinha de milho, suco e schimier ${ }^{15}$.

Tabela 4. Composição das "sacolas" de produtos adquiridos pelo PAA e distribuídos aos beneficiários consumidores no município de Canguçu-RS, em 2008.

\begin{tabular}{|c|c|c|}
\hline Produto & $\begin{array}{l}\text { Sistema de } \\
\text { cultivo }\end{array}$ & $\begin{array}{l}\text { Quantidade/ } \\
\text { sacola* }\end{array}$ \\
\hline Abóbora & Ecológico & $6 \mathrm{~kg}$ \\
\hline Arroz & Convencional & $4 \mathrm{~kg}$ \\
\hline Batata doce & Ecológico & $4 \mathrm{~kg}$ \\
\hline Batata inglesa & Ecológico & $4 \mathrm{~kg}$ \\
\hline Bergamota & Ecológico & $2 \mathrm{~kg}$ \\
\hline Beterraba & Ecológico & $2 \mathrm{~kg}$ \\
\hline Cebola & Ecológico & $4 \mathrm{~kg}$ \\
\hline Cenoura & Ecológico & $2 \mathrm{~kg}$ \\
\hline Couve & Ecológico & $1 \mathrm{~kg}$ \\
\hline Farinha de milho & $\begin{array}{l}\text { Ecológico/ } \\
\text { convencional** }\end{array}$ & $2 \mathrm{~kg}$ \\
\hline Feijão preto & $\begin{array}{l}\text { Ecológico/ } \\
\text { convencional** }\end{array}$ & $4 \mathrm{~kg}$ \\
\hline Laranja & Ecológico & $3 \mathrm{~kg}$ \\
\hline Mandioca & Ecológico & $3 \mathrm{~kg}$ \\
\hline Mel de abelhas & Convencional & $1 \mathrm{~kg}$ \\
\hline Ovos coloniais & Ecológico & $1 \mathrm{dz}$ \\
\hline Peixe em posta & Convencional & $1 \mathrm{~kg}$ \\
\hline Repolho & Ecológico & $3 \mathrm{~kg}$ \\
\hline $\begin{array}{l}\text { Schimier de } \\
\text { frutas }\end{array}$ & Ecológico & 1 pote $(700 \mathrm{~g})$ \\
\hline Suco de frutas & Ecológico & 1 litro \\
\hline
\end{tabular}

* Quantidade condicionada à sazonalidade de produção.

** Parte da produção é ecológica, sendo a outra convencional. Fonte: Pesquisa de campo (2009).

Destaca-se ainda o fato da maioria dos produtos ser oriunda de sistemas de cultivos de base ecológica. Sabidamente, estes alimentos possuem, além de seu valor intrínseco, uma qualidade superior aos produtos considerados convencionais. É o que destaca, em sua fala, uma das nossas entrevistadas,

\begin{abstract}
Os produtos ecológicos pros beneficiários são muito bons e bem aceitos [...] Junto há um trabalho da Assistência social, com as nutricionistas... com a economia doméstica, para que haja o melhor aproveitamento dos produtos recebidos. Para não haver desperdício, sejam bem aproveitados. (Informação verbal ${ }^{16}$ ).
\end{abstract}

O PAA possui um limite anual de recursos disponibilizados a cada agricultor familiar. $\mathrm{Na}$ modalidade Doação simultânea, em 2003, esta cota máxima anual era de $R \$ 2.500,00$, valor correspondente a treze

15 Trata-se de doce em pasta, de origem germânica, feito a partir da polpa de frutas especialmente uva, morango, laranja, pêssego e inclusive abóbora.

${ }^{16}$ Informação fornecida por B.M.B.B. (pedagoga e integrante do comitê do PAA) em entrevista realizada em dez./2009. 
salários mínimos, ou seja, uma média de um salário mínimo mensal mais o décimo terceiro salário. Em 2006 houve um reajuste deste valor, passando então a $\mathrm{R} \$$ 3.500,00 ao ano. Nota-se uma defasagem em relação ao parâmetro inicial utilizado. Em 2009, ocorre novamente uma correção do limite anual, fixado então em $\mathrm{R} \$$ $4.500,00$ por agricultor, valor que outra vez se distancia daquele padrão utilizado em sua gênese.

Esta questão se apresenta como recorrente entre os entrevistados, que em sua ampla maioria $(80,0 \%)$ consideraram tal valor baixo ou muito baixo. $\mathrm{O}$ limite anual foi apontado inclusive como um entrave a uma maior adesão por parte dos agricultores ao PAA. Quando os entrevistados eram solicitados a indicar um valor adequado como cota anual, notamos que estes não indicavam grandes quantias, tanto que o valor médio apontado foi de $\mathrm{R} \$ 6.830,50$, sendo o valor máximo indicado de $\mathrm{R} \$ 10.000,00$.

Ainda em relação à questão do valor correspondente aos produtos entregues pelos agricultores ao PAA, elaboramos a Tabela 5, que expõe os estratos de valores nos quais nossos entrevistados se enquadraram. A maior parte destes, ou seja, $63,3 \%$ se enquadra no estrato máximo, sendo que dentre estes prevaleceram aqueles que entregaram o limite máximo de $\mathrm{R} \$ 3.500,00$ no ano agrícola analisado.

Tabela 5. Distribuição dos entrevistados de acordo com os estratos de renda obtida através da comercialização dos seus produtos ao PAA entre 2008/2009.

\begin{tabular}{ccc}
\hline Estratos & $\begin{array}{c}\text { Número de } \\
\text { famílias }\end{array}$ & $\begin{array}{c}\text { Percentual } \\
(\%)\end{array}$ \\
\hline $\mathrm{R} \$ 1,00-1.000,00$ & 04 & 6,7 \\
$\mathrm{R} \$ 1.001,00-2.000,00$ & 08 & 13,7 \\
$\mathrm{R} \$ 2.001,00-3.000,00$ & 10 & 16,7 \\
$\mathrm{R} \$ 3.001,00-3.500,00$ & 38 & 63,3 \\
\hline Total & $\mathbf{6 0}$ & $\mathbf{1 0 0 , 0}$ \\
\hline
\end{tabular}

Fonte: Pesquisa de Campo (2009).

Quanto às rendas obtidas através da atividade agrícola, observamos que as famílias apresentaram uma amplitude bastante elevada. Todavia, há que sopesar o fato que várias unidades produtivas possuíam outras rendas, provenientes de atividades não agrícolas e de transferências governamentais (previdência social e programas sociais).

A maior renda agrícola bruta anual observada entre os entrevistados foi de $\mathrm{R} \$ 106.875,00$ e a menor renda correspondeu a $\mathrm{R} \$ 661,70$, ficando um valor médio em $\mathrm{R} \$ 28.219,78$. Ressaltamos que na família que apresentou a menor renda, a atividade agrícola respondeu apenas por uma pequena parte dos ingressos, sendo a atividade não agrícola a responsável pela maior parcela da renda familiar total. No entanto, de um modo geral o perfil das unidades produtivas demonstrava não haver um alto nível de tecnificação ou a adoção de sistemas intensivos de produção. Cabe destacar, que 29 das 60 famílias entrevistadas obtiveram renda agrícola bruta inferior a $\mathrm{R} \$ 20.000,00$ anuais. Nestes estabelecimentos o PAA contribuiu de forma bastante expressiva na composição da renda agrícola familiar.

Ressalta-se ainda que os entrevistados que não apresentaram altos ingressos monetários provenientes da produção agropecuária, possuíam, com raras exceções, uma característica bastante peculiar, qual seja, mantinham uma produção bastante diversificada, cujo objetivo primordial era a produção de alimentos para atender as necessidades do grupo doméstico, destinando-se apenas uma parcela da produção para o mercado. Isto ficou evidente conforme vários depoimentos,

Em primeiro lugar a gente tem que pensar em produzir para comer. Não adianta comprar tudo. Quem só planta fumo compra tudo no supermercado. Aí também não adianta... a gente produz tudo o que consome. (Informação verballi ${ }^{17}$ ).

$\mathrm{Na}$ agricultura, uma cultura só não funciona. Se não tem a batata, o feijão... aí não funciona. Se tem que comprar tudo, aí não dá certo. (Informação verbal ${ }^{18}$ ).

Eu acho que no mínimo quatro coisas um agricultor tem que ter na lavoura. Senão acaba tendo que comprar toda a comida e vira tudo em despesa. A gente sempre planta prá consumir. (Informação verbal ${ }^{19}$ ).

Sobre este perfil de agricultor, o PAA exerceu uma interessante influência, pois possibilitou que este continuasse a desempenhar suas atividades tradicionais, inclusive propiciando melhorias e investimentos na unidade produtiva, a partir de uma renda garantida através do fornecimento ao programa e incentivo a outros canais de comercialização, não obstante a venda de gêneros na própria comunidade para aqueles agricultores altamente especializados em determinados cultivos. Assim sendo, acreditamos que este contingente de famílias, através do PAA, teve fortalecida sua estratégia de reprodução social.

Ademais, a manutenção ou mesmo o incremento das práticas de autoconsumo foi igualmente fortalecido a partir do ingresso de nossos entrevistados no PAA. Conforme aponta a Tabela.6, nenhum dos

\footnotetext{
${ }^{17}$ Informação fornecida por A.M.S. (agricultor familiar) em entrevista concedida em Canguçu - RS, Dez./09.

${ }^{18}$ Informação fornecida por L.T. (agricultor familiar) em entrevista concedida em São Lourenço do Sul-RS, Out./09.

${ }^{19}$ Informação fornecida por G.L.B.(agricultor familiar) em entrevista concedida em São Lourenço do Sul-RS, Out./09.
} 
entrevistados relatou que a dieta alimentar da família tenha sido afetada no sentido da diminuição da ingestão de frutas e hortaliças no período recente, ao passo que 30 agricultores afirmaram não terem alterado sua dieta, em que pese o fato de que outros 30 entrevistados indicaram que houve um aumento do consumo destes produtos ao serem produzidos com o fito de atender ao PAA, processo que aparece claramente identificado com a lógica desse programa.

Tabela 6. Opinião dos entrevistados segundo a condição da evolução da dieta alimentar após o respectivo ingresso no PAA.

\begin{tabular}{ccc}
\hline Condição & $\begin{array}{c}\text { Número de } \\
\text { famílias }\end{array}$ & $\begin{array}{c}\text { Percentual } \\
(\mathbf{\%})\end{array}$ \\
\hline Aumentando & 30 & 50,0 \\
Não se alterou & 30 & 50,0 \\
Diminuindo & 0 & 0,0 \\
\hline Total & $\mathbf{6 0}$ & $\mathbf{1 0 0 , 0}$ \\
\hline
\end{tabular}

Fonte: Pesquisa de Campo (2009).

Destaca-se, ainda, que a metade das famílias pesquisadas afirmou ter ampliado o número de cultivos a partir do ingresso no programa, o que parece ter influenciado positivamente na condição de alimentação das famílias, conforme já destacamos. Neste sentido, alguns relatos nos auxiliam a compreender esta situação,

Antes quando queria se comer bem, se ia ao restaurante na cidade. Ali se dizia que se comia bem. Agora eu acho que aqui em casa a gente tem a mesma diversidade do restaurante. Não perdemos em nada pros restaurantes e com a vantagem de ser um produto de qualidade, sem veneno e adubo químico. Tudo saudável e produzido na propriedade. (Informação verbal ${ }^{20}$ ).

Se come mais porque se tem mais produtos disponíveis. As verduras ajudam a ter mais opções. Vai da lavoura para a mesa. (Informação verbal ${ }^{21}$ ).

A gente tomava remédio pra pressão... agora com uma alimentação saudável e o trabalho que a gente faz, não precisamos mais de remédio. Se alimentando bem, a saúde melhora. (Informação verbal ${ }^{22}$ ).

Fica muito evidente a relação existente entre diversificação produtiva e qualidade da alimentação que fomenta a perspectiva de segurança alimentar da família dos agricultores que foram por nós entrevistados. Chamou-nos a atenção a associação feita por diversos entrevistados, relacionando a saúde com a qualidade da alimentação. Quando os agricultores eram questionados

\footnotetext{
${ }^{20}$ Informação fornecida por E.D.B. (agricultor familiar) em entrevista concedida em São Lourenço do Sul-RS, Nov./09.

${ }^{21}$ Informação fornecida por A.E.C. (agricultor familiar) em entrevista concedida em Pelotas-RS, Nov./09.

22 Informação fornecida por G.O. (agricultor familiar) em entrevista concedida em Canguçu-RS, Dez./09.
}

sobre o porquê da aquisição dos produtos da agricultura familiar pelos mercados institucionais, vários entrevistados afirmaram tratar-se de uma opção vinculada à saúde da população, que segundo estes, seria favorecida pelo consumo de alimentos mais saudáveis.

Mesmo com o fornecimento ao PAA, a questão da comercialização para os gêneros produzidos nos estabelecimentos investigados foi apontada como uma dificuldade pela maioria dos agricultores ouvidos. Nada menos que $73,3 \%$ dos entrevistados afirmaram que já haviam perdido parte significativa da sua produção por não ter para quem vendê-la,

Cebola se perdeu... se perdeu muita. Isso faz uns 13 anos. Não tinha prá quem vender né. Nós plantemo doze anos seguidos e só conseguimo ter renda em um ano só. Aos poucos a gente então foi parando com a cebola. Era uma região de muita produção e hoje praticamente já ninguém mais planta. (Informação verbal23).

O pêssego numa safra apodreceu todo. A fábrica sempre prometia de carregar e aí foi se perdendo e acabaram não comprando nada da gente. Isso muita gente perdeu assim. (Informação verbal24).

Falta de compradores, preço baixo, muita produção e a nossa batata acabou apodrecendo toda dentro do galpão. Chegamos a levar de carrinho de mão para fora do galpão. A gente dava de graça e não tinha quem quisesse. (Informação verbal25).

Em vários destes casos, esta condição de dificudades no acesso aos mercados ocasionou o abandono ou a drástica diminuição daquele cultivo. Não raras vezes, a substituição verificada convergiu no abandono do cultivo de batata ${ }^{26}$ ou cebola em favor do plantio de tabaco sob regime de integração vertical com as fumageiras.

Com efeito, interessava-nos averiguar se o PAA havia causado algum impacto positivo nas expectativas da família com relação ao futuro da sua atividade no meio rural. Assim sendo, buscamos examinar se os agricultores alimentavam o desejo de que seus filhos permanecessem ou não na agricultura. Desconsiderandose os seis beneficiários que não possuem filhos, $72,2 \%$ gostariam que os filhos permanecessem na agricultura; $16,7 \%$ não gostariam e $11,1 \%$ não souberam ou não

\footnotetext{
${ }^{23}$ Informação fornecida por D.R.C. (agricultor familiar) em entrevista concedida em Canguçu-RS, Dez./09.

24 Informação fornecida por A.E.C. (agricultora familiar) em entrevista concedida em Pelotas-RS, Nov./09.

25 Informação fornecida por C.A.S. (agricultor familiar) em entrevista concedida em São Lourenço do Sul-RS, Dez./09.

${ }_{26}$ Destaca-se que São Lourenço do Sul já ocupou, durante os anos 1980, o posto de município com a maior produção deste tubérculo a nível nacional. No entanto, nos dias atuais a produção local de batata sequer cobre a demanda local, estando este cultivo tradicional em processo de franca decadência.
} 
quiseram responder esta questão. No que concerne ao aspecto sucessório, $61,7 \%$ das famílias prevêem a existência de sucessor; $5,0 \%$ não vislumbram nenhum sucessor e 33,3\% não souberam ou não quiseram informar.

Ainda que estes dados não exprimam uma situação entusiasmante quanto ao futuro que a família projeta para a sua unidade produtiva, do ponto de vista de sua permanência ou continuidade no meio rural, ressaltamos que os resultados obtidos com os beneficiários do PAA são bem mais otimistas se comparados com outros estudos realizados nesta mesma região geográfica, a exemplo da pesquisa feita por Silva ${ }^{[18]}$ com os beneficiários de uma outra política pública, o Banco da Terra ${ }^{27}$. Há que se ter em mente ainda, que vários dos agricultores entrevistados indicavam que seus filhos já haviam deixado a atividade agrícola, muito em decorrência das sucessivas crises que vêm acometendo esta atividade no extremo sul gaúcho.

Cabe destacar ainda que nenhuma das famílias avaliadas manifestou a expressa intenção de abandonar a unidade produtiva e instalar-se na cidade. Mesmo apresentando queixas em relação à atividade agrícola, a questão de residir no meio rural sempre era destacada como fundamental em seu imaginário.

Algo, que ao nosso entender, é um aspecto diferencial dos agricultores fornecedores ao PAA em relação aos demais agricultores familiares da região em que o estudo foi realizado, é o fato de que a esmagadora maioria $(93,3 \%)$ dos nossos entrevistados ter afirmado que recebeu algum tipo de assistência técnica no último ano agrícola. Sabidamente, a falta de assistência técnica disponibilizada às unidades produtivas tem sido apontada como um grande entrave ao desenvolvimento das formas familiares de produção. Assim sendo, os fornecedores ao PAA podem ser considerados como privilegiados por contarem com este tipo de serviço, que certamente os auxilia no planejamento das suas atividades produtivas e na organização social da produção, conforme pudemos observar no trabalho de campo. Poderíamos afirmar que o PAA não é uma ação isolada, estando geralmente associado a outros processos e políticas públicas que devem ser levados em conta na avaliação de seu real alcance.

Quanto às novas possibilidades advindas da operação com o PAA, 91,7\% dos entrevistados afirmaram que o programa trouxe novas perspectivas

${ }^{27}$ Nesta pesquisa, realizada com os assentados pelo Banco da Terra em Canguçu, apenas $48,3 \%$ das famílias previram um sucessor, $23,3 \%$ não vislumbram nenhum sucessor e $28,4 \%$ não souberam informar. para as suas atividades e permanência da família no meio rural. Grande parte destas pessoas identificou na garantia de venda de parte da sua produção como o fator que mais interferiu positivamente para o estabelecimento de uma nova dinâmica propiciada pelo ingresso da família no PAA.

Uma das maiores virtudes do PAA parece estar na sua tentativa de conjugar três importantes etapas, quais sejam, a produção, a comercialização e o consumo, contemplando especificamente diversos grupos sociais que, em boa medida, encontravam-se à margem dos processos produtivos ou que por determinadas circunstâncias, estavam submetidos a uma condição de reduzidas perspectivas no que concerne à sua reprodução social enquanto agricultores familiares.

Neste sentido, ficou muito evidente o impacto provocado pelo PAA na comunidade quilombola que fornece alimentos ao programa. Conforme depoimento, foi a partir da produção de base ecológica e do fornecimento de produtos ao PAA, que se alterou, substancialmente, o cenário da comunidade.

As famílias passaram a comer mais e melhor, incluindo hortaliças... é mais saudável e houve esse incentivo para produzir alimentos saudáveis. A partir do PAA também, uma parte daqueles que trabalhavam de empregado nos vizinhos, começaram a se dedicar mais em plantar a sua área, mesmo que a terra que a gente tenha é pouca. (Informação verbal ${ }^{28}$ ).

As mudanças identificadas no discurso deste entrevistado denotam uma grande virtude que se deve associar ao PAA. Mesmo que outros fatores identificados, tenham contribuído para a situação descrita acima, o PAA há que ser visto como propulsor de novas possibilidades de comercialização da produção e de obtenção de renda para estas famílias.

A exigência imposta pelo PAA de os fornecedores estarem vinculados à alguma associação ou cooperativa representa uma seleção, um filtro social, que determina o ingresso no programa de agricultores com um determinado perfil. A característica organizativa confere uma similaridade ao grupo de agricultores pesquisados, não se referindo exclusivamente ao número de instituições as quais estes se encontram associados, mas igualmente pelo grau de importância conferido pelos entrevistados a este processo social. Não obstante, os próprios agricultores reconheciam a necessidade de estarem organizados em associação para aumentarem as suas possibilidades de acessarem os mercados e

\footnotetext{
28 Informação concedida por J.E.Q. (agricultor quilombola) em entrevista concedida em São Lourenço do Sul, Nov./09.
} 
melhorarem suas condições de existência social. Isto pode ser observado claramente em alguns depoimentos como: "Tem que estar organizado e ter algum diferencial... do jeito 'tradicional' não dá mais." (Informação verbal ${ }^{29}$ ). "Se não tiver uma cooperativa, estar associado, não se consegue... individualmente é muito difícil." (Informação verbal ${ }^{30}$ ).

No nosso entendimento, a inserção dos agricultores em diversas organizações sociais propicia a estes uma forma de sociabilidade que os coloca num outro patamar de compreensão da realidade em que estão inseridos, o que faz com que estes disponham de mais alternativas no afã de planejar e desenvolver as suas atividades.

\section{Considerações finais}

Em um cenário de especialização produtiva, marcado pela crescente perda de autonomia e pelas reduzidas alternativas de desenvolvimento rural, os agricultores do sul gaúcho puderam contar, a partir de 2003, com uma política pública que visava atuar justamente neste escopo. Avaliar o impacto provocado pelo PAA nas famílias rurais beneficiadas foi o objetivo deste estudo, realizado com os beneficiários deste programa.

Neste sentido, evidenciamos que $91,7 \%$ das familias entrevistas tiveram alteradas positivamente as suas expectativas quanto ao futuro na atividade agrícola, através da garantia de comercialização de parte, ou mesmo, de toda a sua produção, via fornecimento ao PAA. Não obstante, houve um incremento na dieta alimentar de exatamente metade dos nossos entrevistados. Assumindo que a alteração dos hábitos alimentares não é um processo simples, este percentual pode ser considerado como bastante expressivo, haja vista a qualidade da alimentação destacada por diversas famílias. De igual modo, o autoconsumo estaria sendo, consequentemente, fortalecido através do resgate de certas práticas e iniciativas.

A diversificação produtiva, através da ampliação dos cultivos e rendas, foi proporcionada pelo PAA em $41,7 \%$ das unidades produtivas pesquisadas, sendo que em outras $51,7 \%$ das famílias não houve alteração dos produtos cultivados. Se considerarmos que deste último grupo de famílias, boa parte já possuía um nível de diversificação em seus estabelecimentos, o PAA

\footnotetext{
${ }^{29}$ Informação concedida por G.O. (agricultor familiar) em entrevista fornecida em Canguçu-RS, Dez./09.

${ }^{30}$ Informação concedida por E.H.B. (agricultor familiar) em entrevista fornecida em Pelotas-RS, Nov./09.
}

contribuiu para a manutenção desta dinâmica produtiva. Assim sendo, também o programa teria auxiliado a uma parcela dos agricultores a sustentarem suas atividades tradicionais como é o caso do fabrico de doces artesanais como no caso do schmier.

Pudemos comprovar, nesta pesquisa, a importância assumida pelos mercados institucionais, a exemplo do PAA, em promover a diversificação produtiva desta forma social de produção, interferindo positivamente nas questões atinentes à segurança alimentar e nutricional dos agricultores familiares implicados neste processo. Da mesma forma, as perspectivas com relação ao futuro por parte das familias beneficiadas a partir do ingresso no programa, também foi verificada. Não obstante, as adversidades inerentes à atividade agrícola apareceram como uma grande preocupação por parte de vários dos entrevistados.

A aproximação aqui realizada sobre a dinâmica do PAA é obviamente limitada diante das restrições que enfrentamos no sentido de ampliar o número de entrevistados numa região consideravelmente grande, correspondente ao extremo sul gaúcho. Nesse sentido, entendemos a importância da realização de novos estudos que permitam cotejar os logros conquistados por essa política pública para além da mera compilação de dados estatísticos. Com efeito, nosso estudo demonstrou um aspecto que reputamos como crucial para avaliar programas dessa natureza, qual seja, o que evidencia o resgate da autoestima das famílias rurais a partir do momento em que ingressam no programa e cumprem o desiderato de fornecerem alimento a outros setores da população. Esse aspecto, ineludivelmente, há que ser levado em conta na análise do PAA.

Não menos importante está a questão de representar uma oportunidade de romper com o mito de que os mais pobres estejam obrigados a consumirem produtos de qualidade inferior. Esse aspecto é irrefutável se nos atemos ao fato de uma criança de escola pública, oriunda de família de baixa renda, esteja consumindo diariamente produtos frescos ou transformados com esses atributos que até então se reconhecia como próprios dos mercados direcionados às classes mais acomodadas de nossa sociedade. Possivelmente esteja aí uma das grandes virtudes do PAA que devam ser levadas em conta em toda e qualquer avaliação desse programa.

Por outro lado, a ampliação do mercado institucional poderá representar uma excelente alternativa para viabilizar a melhoria das condições de reprodução social na agricultura familiar, promovendo ações estratégicas de desenvolvimento dos territórios, voltadas 
à valorização dos modos de vida tradicionais e à produção de alimentos em sistemas sustentáveis de produção. Todavia, estes processos representam outros desdobramentos que afetam ao tema da segurança alimentar e nutricional das populações envolvidas.

\section{Referências Bibliográficas}

1. ABRAMOVAY, R. Paradigmas do capitalismo agrário em questão. São Paulo: Hucitec / ANPOCS / UNICAMP, 275 p.,1992.

2. BRASIL, Instituto Brasileiro de Geografia e Estatística - IBGE. Censo Agropecuário 2006. Disponível em: $<$ http://www.ibge.gov.br/home/estatistica/economia /agropecuaria/censoagro/2006/default.shtm>. Acesso em 10/11/2009.

3. SEN, A. Desenvolvimento como liberdade. São Paulo: Companhia das Letras, 2002.

4. BELIK, W. Perspectivas para segurança alimentar e nutricional no Brasil. Saúde e Sociedade, São Paulo, v. 12, n. 1, p. 12-20, jan.-jun. 2003.

5. MALUF, RSJ. O novo contexto internacional do abastecimento e da segurança alimentar. In: In: BELIK, W.; MALUF, R. S. (Org.). Abastecimento e Segurança Alimentar: os limites da liberalização. Campinas (SP): IE/UNICAMP, p. 37-63. 2000.

6. SACCO DOS ANJOS, F.; GODOY, WI.; CALDAS, NV. As feiras-livres de Pelotas sob o império da globalização: perspectivas e tendências. $1^{\text {a }}$ ed., Pelotas, Editora e Gráfica da UFPel, 2005.

7. VALENTE, FLS. O direito humano à alimentação: desafios e conquistas (Org.), São Paulo: Cortez, 2002.

8. SACCO DOS ANJOS, F.; CALDAS, NV.; HIRAI, WG. Mercantilização da agricultura e insegurança alimentar no sul do Brasil. In: XLV CONGRESSO DA SOBER. Anais (cd room)... Rio Branco, 2008.

9. TAKAGI, M.; DEL GROSSI, ME.; GRAZIANO DA SILVA, J. O Programa Fome Zero dois anos depois. Disponível em: $<\underline{\text { http://www.rlc.fao.org/es/prioridades/seguridad/in }}$ greso/pdf/zero-por.pdf $>$. Acesso em 02/03/2009.
10. MATTEI, L. Estudo do impacto e da sustentabilidade do Programa de Aquisição de Alimentos-PAA, nas regiões sul e nordeste do país. S.l.: s.n., 2006.

11. BRASIL. Instituto Brasileiro de Geografia e Estatística - IBGE. SIDRA (Sistema IBGE de Recuperação Automática). Disponível em: $<$ http://www.sidra.ibge.gov.br $>$. Acesso em $21 / 07 / 2009$.

12. HIRAI, WG. Agricultura familiar e segurança alimentar: a importância da produção para o autoconsumo em três municípios do RS. Pelotas. SPAF/UFPel. Dissertação de Mestrado. 2008.

13. IPARDES - Instituto Paranaense de Desenvolvimento Econômico e Social. O mercado de orgânicos no Paraná: caracterização e tendências. Curitiba, 2007.

14. MULLER, AL. A construção das políticas públicas para a agricultura familiar no Brasil: o caso do Programa de Aquisição de Alimentos. Porto Alegre. PGDR/UFRGS. Dissertação de Mestrado. 2007.

15. YIN, RK. Estudo de Caso: Planejamento e Métodos. $3^{\circ}$ Edição. Porto Alegre: Bookman, 2005, 212p.

16. GRANDO, MZ. Pequena agricultura em crise: o caso da "Colônia Francesa" no Rio Grande do Sul. Porto Alegre: Teses FEE, n.14. 1989.

17. GLIESSMAN, SR. Agroecologia: Processos ecológicos em agricultura sustentável. Porto Alegre: Ed. Universidade/UFRGS. 2001.

18. SILVA, FN. da. Agricultura familiar e políticas públicas: estudo sobre o Banco da Terra no município de Canguçu, RS. Pelotas. SPAF/UFPEL. Dissertação de Mestrado. 2009.

\section{Agradecimentos}

Os autores do artigo agradecem os apoios recebidos do CNPq (Conselho Nacional de Desenvolvimento Científico e Tecnológico) por meio da concessão de bolsa de mestrado e de bolsa de produtividade, e da Coordenação de Aperfeiçoamento de Pessoal de Nível Superior - CAPES, mediante Acordo hispano-brasileiro de Cooperação e Intercâmbio no 186/09, sem os quais esse trabalho não poderia ter sido realizado. 